\title{
The Production of Biogenic Silica from Different South African Agricultural Residues through a Thermo-Chemical Treatment Method
}

\author{
Ncamisile Nondumiso Maseko ${ }^{1}$, Denise Schneider ${ }^{2}{ }^{D}$, Susan Wassersleben ${ }^{3}$, Dirk Enke ${ }^{1,3}$, \\ Samuel Ayodele Iwarere ${ }^{4, *(\mathbb{D})}$, Jonathan Pocock ${ }^{1}$ and Annegret Stark ${ }^{1,5}$ (D) \\ 1 Discipline of Chemical Engineering, University of KwaZulu-Natal, 238 Mazisi Kunene Road, Glenwood, \\ Durban 4041, South Africa; masekon@ukzn.ac.za (N.N.M.); dirk.enke@uni-leipzig.de (D.E.); \\ pocockj@ukzn.ac.za (J.P.); starka@ukzn.ac.za (A.S.) \\ 2 3P Instruments GmbH \& Co. KG, Rudolf-Diesel-Str. 12, 85235 Odelzhausen, Germany; \\ denise.schneider@3P-instruments.com \\ 3 Institute of Chemical Technology, Universität Leipzig, Linnéstr. 3, 04103 Leipzig, Germany; \\ susan.wassersleben@uni-leipzig.de \\ 4 Department of Chemical Engineering, University of Pretoria, Lynnwood Road, Hatfield, \\ Pretoria 0028, South Africa \\ 5 SMRI/NRF SARChI Research Chair in Sugarcane Biorefining, Durban 4001, South Africa \\ * Correspondence: samuel.iwarere@up.ac.za; Tel.: +27-12-420-4111
}

check for updates

Citation: Maseko, N.N.; Schneider, D.; Wassersleben, S.; Enke, D.; Iwarere, S.A.; Pocock, J.; Stark, A. The Production of Biogenic Silica from Different South African Agricultural Residues through a Thermo-Chemical Treatment Method. Sustainability 2021, 13, 577. https://doi.org/10.3390/ su13020577

Received: 5 December 2020 Accepted: 7 January 2021 Published: 9 January 2021

Publisher's Note: MDPI stays neutral with regard to jurisdictional clai$\mathrm{ms}$ in published maps and institutional affiliations.

Copyright: (C) 2021 by the authors. Licensee MDPI, Basel, Switzerland. This article is an open access article distributed under the terms and conditions of the Creative Commons Attribution (CC BY) license (https:// creativecommons.org/licenses/by/ $4.0 /)$.

\begin{abstract}
A thermo-chemical treatment method was used to produce biogenic amorphous silica from South African sugarcane and maize residues. Different fractions of South African sugarcane (leaves, pith, and fiber) were processed for silica production. The biomass samples were leached with either $7 \mathrm{wt} \%$ citric acid or $7 \mathrm{wt} \%$ sulfuric acid at $353 \mathrm{~K}$ for $2 \mathrm{~h}$ prior to being rinsed, dried and combusted using a four-step program ranging from room temperature to $873 \mathrm{~K}$ in a furnace. The characterization of the pre-treated biomass samples was conducted using thermogravimetric analysis (TG/DTA), X-ray fluorescence analysis (XRF) and elemental analysis (CHN), while the final products were characterized by XRF, X-ray diffraction (XRD), elemental analysis, nitrogen physisorption and scanning electron microscopy (SEM). Citric acid pre-treatment proved to be an attractive alternative to mineral acids. Amorphous biogenic silica was produced from sugarcane leaves in good quality ( $0.1 \mathrm{wt} \%$ residual carbon and up to $99.3 \mathrm{wt} \%$ silica content). The produced biogenic silica also had great textural properties such as a surface area of up to $323 \mathrm{~m}^{2} \mathrm{~g}^{-1}$, average pore diameter of $5.0 \mathrm{~nm}$, and a pore volume of $0.41 \mathrm{~cm}^{3} \mathrm{~g}^{-1}$.
\end{abstract}

Keywords: biogenic amorphous silica; green chemistry; maize leaves; sugarcane fiber; sugarcane leaves; sugarcane pith

\section{Introduction}

Plants can either be classified as silica accumulators or silica non-accumulators. Sugarcane, maize, and other types of Gramineae (grasses) fall under silica accumulators. Besides water, agricultural residues such as maize leaves or sugarcane leaves, pith, and fiber consist of cellulose, hemicellulose, lignin, as well as inorganic matter that is generally referred to as ash. Extensive research has been conducted to extract biogenic silica from different agricultural residues such as rice husk [1,2], wheat straw and cereal remnant [3], rice straw, oat husk and spelt husk [4], and corn cob [5].

Biogenic silica can be obtained, e.g., from diatomite. However, this procedure utilizes complex thermal and mechanical treatments that result in biogenic silica with impurities like $\mathrm{CaO}, \mathrm{FeO}_{3}$, and $\mathrm{Al}_{2} \mathrm{O}_{3}$ [6]. Hence the production of high-quality porous silica from silica accumulating plants has become an area of interest to most researchers [1-5]. For the production of silica from biomass, pre-treatment of the biomass by leaching prior 
to combustion is essential as it improves the purity of the ash by increasing the $\mathrm{SiO}_{2}$ content while decreasing the share of all the other inorganic constituents $\left(\mathrm{Cl}^{-}, \mathrm{K}_{2} \mathrm{O}, \mathrm{P}_{2} \mathrm{O}_{5}\right.$, $\mathrm{MgO}$, etc.) [2]. Acid leaching disrupts the lignin-carbohydrate matrix in order to enable cellulose hydrolysis [7]. Inorganic acids (e.g., sulfuric and hydrochloric acid) and bases (e.g., sodium hydroxide and ammonium hydroxide) have been used for biomass leaching in previous studies $[1,8,9]$. Inorganic acid leaching protocols, however, are environmentally unfriendly. They have several drawbacks as they require a lot of water to rinse the biomass post leaching, are not economical since they require the usage of expensive corrosive resistant processing equipment and in addition, a special disposal treatment of the used acids is required. Several researchers have therefore opted for the use of carboxylic acids as are bio-based and economical with no special equipment needed. During the leaching, the carboxylic group is involved in the successful removal of inorganic impurities via a chelating reaction with the metal ions [10].

The importance of the incineration temperature has also been emphasized in literature [3]. Silica can exist in an amorphous form or in a variety of crystalline forms: cristobalite, tridymite, and quartz. Amorphous silica can be partially converted to crystalline silica at approximately $1280 \mathrm{~K}$ in sugarcane-related biomass [11]. Higher temperatures cause the cellular microstructure to collapse, and that results in the merging of the small pores [12]. Consequently, a crystalline phase will form, leading to a reduced specific surface area [12]. The phase-transition temperature, however, is dependent on the presence of impurities in the sample; i.e., the higher the impurity content in a sample, the lower the temperature at which amorphous silica converts to crystalline silica. This makes the incineration protocol an important aspect in removing organics while retaining amorphous silica from biomasses.

Sugarcane (scientifically known as Saccharum officinarum) is one of the principal agricultural crops that are cultivated in tropical countries. The annual world production of sugarcane in 2018/2019 was approximately 1904 million tons (of which approximately 19 million tons are produced in South Africa [13]. From the produced volume, approximately 279 million metric tons of biomass residues are generated worldwide [14], with South Africa responsible for about 2 million metric tons [15]. Sugarcane residues mainly consist of leaves and bagasse, where the bagasse can be further separated into fiber and pith. Maize (Zea mays L.) is the most important grain crop in South Africa, which is produced throughout the country. Approximately 8 million tons of maize are produced in South Africa annually, and a significant percentage of leaves are produced as trash [16].

In South Africa, $90 \%$ of the sugarcane is burnt prior to harvest to facilitate cane cutting and to reduce fungus as well as other plant disease growth on the soil, while $10 \%$ is harvested green [17]. The burning of the sugarcane leaves prior to harvest is not environmentally friendly as it causes pollution and health-related issues [11]. Fiber and pith can be produced from excess sugarcane bagasse, which is otherwise used in boilers in the sugarcane mills to generate steam, giving an opportunity to process them to value added materials. Maize leaves are used to feed livestock in rural areas, while they have no significant use in most urban areas. Silica has been exploited in several applications across many fields such as electronics, image sensing, solar power conversion and as a precursor for silicon production (the birth of semiconductor evolution) [18]. Silica has been used in desiccant packets for specimen storage [19], the manufacturing of toothpaste [20], and to synthesize amorphous silica nanowires [21].

Several studies that utilize citric acid as a biomass leaching agent have been conducted by various researchers $[2,4,10,22]$. Selective results obtained from the literature are reported in Table 1. All the presented results in Table 1 are based on pre-treatment methods that employed only carboxylic/organic acids. Rice husk seems to be the most utilized biomass when it comes to the separation of biogenic silica from agricultural residues. 
Table 1. Comparison of different citric acid pre-treatment conditions for the production of biogenic silica from different biomasses.

\begin{tabular}{|c|c|c|c|c|c|}
\hline Type of Biomass & Pre-Treatment Acid & $\begin{array}{c}\text { Pre-Treatment } \\
\text { Temperature } \\
\text { (K) }\end{array}$ & $\begin{array}{l}\text { Silica Content } \\
\quad(w t \%)\end{array}$ & $\begin{array}{l}\text { BET Surface Area } \\
\left(\mathrm{m}^{2} \mathrm{~g}^{-1}\right)\end{array}$ & References \\
\hline Rice husk & $10 \%(v / v)$ citric acid & 423 & 98.8 & n.d. & [22] \\
\hline Rice husk & $5 \mathrm{wt} \%$ citric acid & 323 & 99.1 & n.d. & [10] \\
\hline Rice husk & $5 \mathrm{wt} \%$ citric acid & 353 & 97.7 & 313 & [2] \\
\hline Rice Straw & & 323 & 99.1 & 264 & {$[4]$} \\
\hline Spelt husk & & & 95.8 & 185 & \\
\hline Oat husk & $3.25 \mathrm{M}$ citric acid & & 99.1 & 248 & \\
\hline Horsetail & & & 91.6 & 301 & \\
\hline
\end{tabular}

n.d: not determined.

There is no substantial existing literature that focuses on the usage of either sugarcane or maize leaves residues. This study focuses on the valorization of South African maize (maize leaves) and sugarcane (sugarcane leaves, pith, and fiber) residues for the first time to produce amorphous biogenic silica using a thermo-chemical method that utilizes an organic acid. This study aimed to demonstrate the effectiveness of citric acid pre-treatment on the utilized South African biomass residues in terms of purity and textural properties despite the nature of the biomass. Hot water pre-treatment and inorganic acid (sulfuric acid) pre-treatment was also carried out for comparison sake. Despite the different physical appearance of these biomasses, they were all handled/utilized the same way in order to highlight the effectiveness of the employed thermochemical method using citric acid as a leaching agent to produce biogenic silica with high silica yield and impressive textural properties. The results obtained from all the utilized biomasses were presented based on ash purity, morphology, textural and structural characteristics.

\section{Materials and Methods}

\subsection{Materials}

Sugarcane and maize leaves were supplied by farmers in Durban, South Africa. Sugarcane fiber and pith were supplied by the Sugar Milling Research Institute (SMRI) in Durban, South Africa. Upon collection, the biomasses were dried in an oven at $375 \mathrm{~K}$ overnight to reduce the moisture content. After drying, the leaves were cut into pieces of about $1.5 \mathrm{~cm}$ long prior to any treatment, while the pith and the fiber were used as supplied.

\subsection{Methods}

\subsubsection{Preparation of Biogenic Silica}

In separate experiments, about $50 \mathrm{~g}$ of each agricultural residue biomass was washed with $1200 \mathrm{~mL}$ distilled water while being agitated for $2 \mathrm{~h}$ at ambient temperature and then dried in the oven at $373 \mathrm{~K}$ overnight prior to leaching with either $1200 \mathrm{~mL}$ hot distilled water, $7 \mathrm{wt} \%$ citric acid or $7 \mathrm{wt} \%$ sulfuric acid (in the case of sugarcane leaves) at $353 \mathrm{~K}$ for $2 \mathrm{~h}$ with continuous stirring. After leaching, the biomass was rinsed with deionized water to remove excess acid, followed by drying at $323 \mathrm{~K}$ for $24 \mathrm{~h}$.

The dried, leached biomass was subjected to sequential combustion at a heating rate of $10 \mathrm{~K} \mathrm{~min}^{-1}$ in a furnace. The incineration program was as follows: $30 \mathrm{~min}$ at $583 \mathrm{~K}$, $60 \mathrm{~min}$ at $723 \mathrm{~K}, 210 \mathrm{~min}$ at $783 \mathrm{~K}$, and lastly $30 \mathrm{~min}$ at $873 \mathrm{~K}$. After cooling of the ash, the resulting samples were kept at room temperature for characterization.

The samples were labeled sugarcane (SC) leaves-raw (for dried but unprocessed sugarcane leaves), SC leaves ash -HW (for the hot distilled water leached sugarcane leaves), SC leaves ash-CA (for citric acid leached sugarcane leaves), SC leaves ash-SA (for sulfuric acid leached sugarcane leaves), SC pith-raw (for dried unprocessed sugarcane pith), SC pith ash-CA (for citric acid leached sugarcane pith), SC fiber-raw (for dried but unprocessed sugarcane fiber), SC fiber ash-CA (for citric acid leached sugarcane fiber), Maize leaves-raw 
(for dried but unprocessed maize leaves) and Maize leaves ash-CA (for citric acid leached maize leaves).

\subsubsection{Characterization of the Biogenic Silica}

A Vario EL micro analyzer system (Heraeus, Hanau, Germany) was used for carbon content analysis, approximately $3 \mathrm{mg}$ of the biomass sample was used. The elemental composition of the specimen was carried out using X-ray fluorescence (XRF) analysis (S4 Explorer, WDXRF Bruker, Karlsruhe, Germany). For this purpose, $0.75 \mathrm{~g}$ of the sample was mixed with $0.25 \mathrm{~g}$ of a wax powder. The mixture was ground to form a fine powder prior to being pressed with a hydraulic press (PerkinElmer, Germany) at 10 tons for 2 min to produce a round pellet with $20 \mathrm{~mm}$ diameter.

The phase identification was carried out using a Seifert XRD 7 apparatus that is equipped with Ni-filtered, $\mathrm{Cu}-\mathrm{K} \alpha$ radiation $(\lambda=1.54 \dot{\mathrm{A}})$. Thermal analysis of the biomass samples was performed using a Thermo Gravimetric/Differential Thermal analyzer TG/DTA equipment (DST2960 simultaneous apparatus, TA Instrument, New Castle, DE, USA) that had a supplement air flow rate of $150 \mathrm{~mL} \mathrm{~min}^{-1}$ and a heating rate of $10 \mathrm{~K} \mathrm{~min}^{-1}$. Approximately $7 \mathrm{mg}$ of each sample was used for the analysis. The operating temperature range was between 293 and $1073 \mathrm{~K}$, while the heating rate was $10 \mathrm{~K} \mathrm{~min}^{-1}$. The surface morphology was studied by Scanning Electron Microscopy (SEM) using an Ultra 55 (Zeiss, Jena, Germany) that was operated at $10 \mathrm{keV}$. Nitrogen sorption analysis was used to determine the textural properties of the biomass samples. This was carried out using an ASAP 2010, Micromeritics, Nocross, GA, USA). Prior to measurements, the biomass samples were degassed for $12 \mathrm{~h}$ at $523 \mathrm{~K}$ under ultra-high vacuum. The relative pressure $\left(\mathrm{p} / \mathrm{p}_{0}\right)$ of 0.995 was used to calculate the total pore volume. The Brunauer-Emmett-Teller (BET) model was used in the relative pressure of the range of $\left(\mathrm{p} / \mathrm{p}_{0}\right)$ between 0.05 and 0.25 to evaluate the specific surface area. The value of $0.162 \mathrm{~nm}^{2}$ was used as cross-sectional area of a nitrogen molecule. The adsorption branch of the isotherm was used to determine the pore size distribution by applying the Barret-Joyner-Halenda (BJH) method [23].

\section{Results and Discussion}

\subsection{Thermal Analysis and Assessment of the Combustion Protocol}

The elemental analysis ( $\mathrm{CHN})$ of the untreated biomass and produced silica ash samples is given in Table 2.

Table 2. Elemental analysis (CHN) for sugarcane and maize-based biomass, as well as the ash derived from the respective biomass samples.

\begin{tabular}{cccc}
\hline Biomass & Nitrogen (\%) & Carbon (\%) & Hydrogen (\%) \\
\hline SC leaves-Raw & $0.40 \pm 0.00$ & $39.50 \pm 0.00$ & $5.42 \pm 0.10$ \\
SC leaves Ash-HW & $0.031 \pm 0.01$ & $0.19 \pm 0.00$ & $0.42 \pm 0.01$ \\
SC leaves Ash-CA & $0.02 \pm 0.00$ & $0.14 \pm 0.01$ & $0.31 \pm 0.00$ \\
SC leaves Ash-SA & $0.01 \pm 0.01$ & $0.02 \pm 0.01$ & $0.12 \pm 0.01$ \\
SC Pith-Raw & $0.10 \pm 0.01$ & $45.30 \pm 0.10$ & $5.80 \pm 0.05$ \\
SC Pith Ash-CA & $0.01 \pm 0.01$ & $0.04 \pm 0.01$ & $0.38 \pm 0.04$ \\
SC Fiber-Raw & $0.03 \pm 0.00$ & $45.20 \pm 0.10$ & $5.90 \pm 0.00$ \\
SC Fiber Ash-CA & $0.01 \pm 0.00$ & $0.03 \pm 0.00$ & $0.14 \pm 0.03$ \\
Maize leaves-Raw & $0.10 \pm 0.00$ & $45.30 \pm 0.10$ & $5.80 \pm 0.10$ \\
Maize leaves Ash-CA & $0.03 \pm 0.01$ & $0.05 \pm 0.01$ & $0.37 \pm 0.04$ \\
\hline
\end{tabular}

In order to assess the combustion method for the biomasses, thermogravimetric analysis (TGA) was conducted (air, $10 \mathrm{~K} \mathrm{~min}^{-1}$, max. temperature $1073 \mathrm{~K}$ ). Figure 1 shows the TG/DTA profiles of the utilized biomass samples, indicating similar decomposition patterns irrespective of the type of biomass. The first observed peak was at $339 \mathrm{~K}, 352 \mathrm{~K}$, $334 \mathrm{~K}$ and $355 \mathrm{~K}$ with a weight loss of 3.7, 7.1, 6.3 and $5.2 \mathrm{wt} \%$ for sugarcane leaves, pith, maize leaves, and sugarcane fiber, respectively. This peak is due to the evaporation of 
moisture and other volatiles. The second observed peak (first degradation peak) occurred at $575 \mathrm{~K}, 578 \mathrm{~K}, 562 \mathrm{~K}$ and $554 \mathrm{~K}$, with a weight loss of 59.8, 54.1, 60.6 and $58.7 \mathrm{wt} \%$ for sugarcane leaves, sugarcane pith, maize leaves and sugarcane fiber, respectively. This peak is due to the thermal degradation of hemicellulose [4].

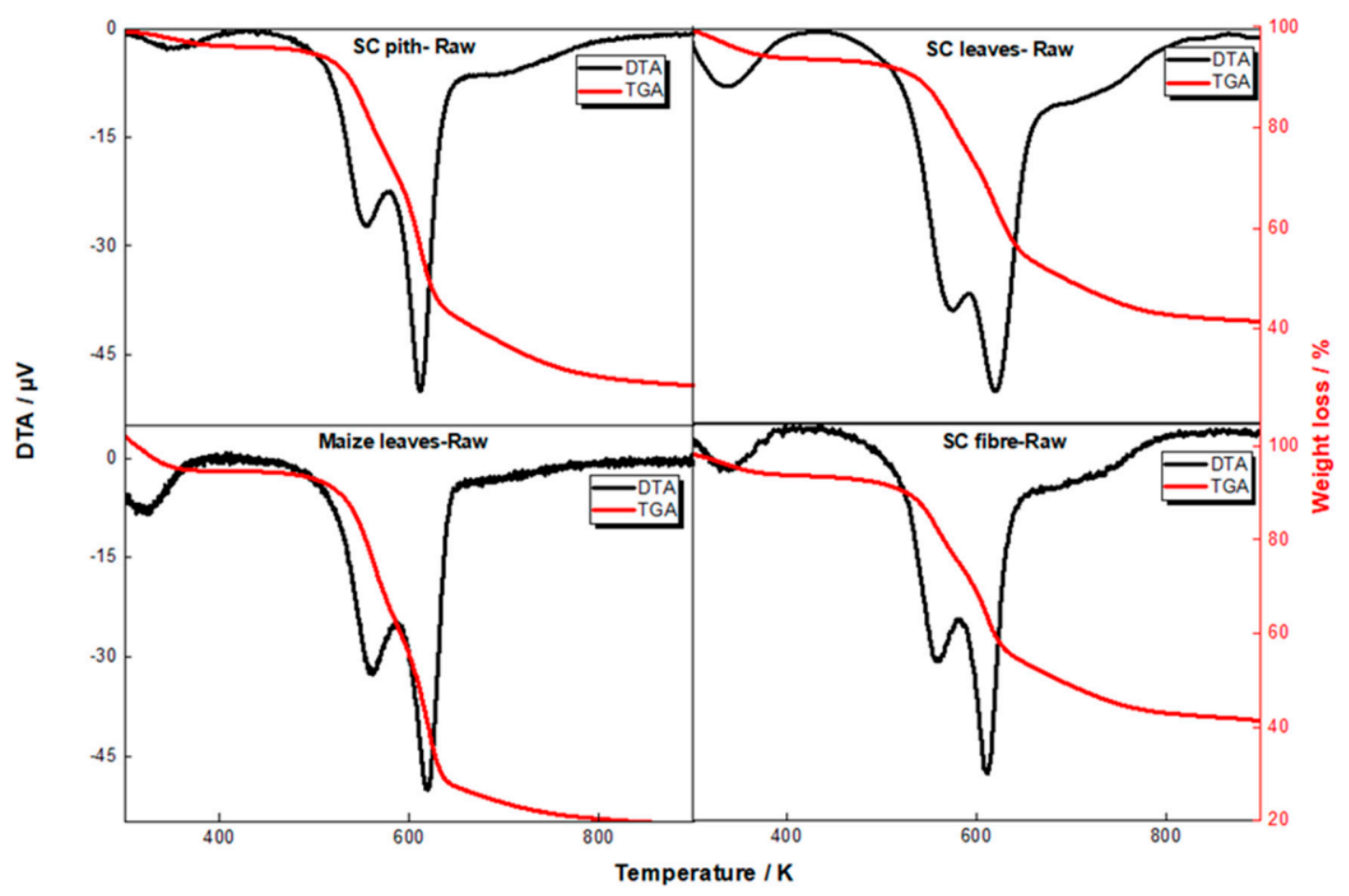

Figure 1. TG/DTA profiles of SC pith-Raw, SC leaves-Raw, Maize leaves-Raw and SC fiber-Raw.

Pure cellulose has been reported to thermally degrade at $628 \mathrm{~K}$ [10]. In the thermograms of the materials investigated herein, the third observed peak (2nd degradation peak) was at $619 \mathrm{~K}, 619 \mathrm{~K}$, and $617 \mathrm{~K}$ with a weight loss of 29.9, 37.7, and $28.9 \mathrm{wt} \%$ for sugarcane leaves, pith, and maize leaves, respectively. Sugarcane fiber exhibited a somewhat lower degradation temperature of $607 \mathrm{~K}$ with a corresponding weight loss of $35.6 \mathrm{wt} \%$. According to Alyosef et al. [2], the presence of high concentrations of potassium and other inorganic species found in biomass samples reduces the thermal stability of cellulose, in line with the results reported in this work: all the biomass samples contain potassium (see Table 3), with the highest potassium concentration found for sugarcane fiber.

Table 3. Chemical analysis of inorganics from sugarcane leaves, pith and fiber, as well as maize leaves, before and after pre-treatment with hot water or acids (determined by XRF).

\begin{tabular}{|c|c|c|c|c|c|c|c|c|c|c|}
\hline Constituent & $\begin{array}{c}\text { SC } \\
\text { Leaves-Raw } \\
(w t \%)\end{array}$ & $\begin{array}{c}\text { SC } \\
\text { Leaves } \\
\text { Ash-HW } \\
(\mathbf{w t} \%)\end{array}$ & $\begin{array}{c}\text { SC } \\
\text { Leaves } \\
\text { Ash-CA } \\
(\mathbf{w t} \%)\end{array}$ & $\begin{array}{c}\text { SC Leaves } \\
\text { Ash-SA } \\
\text { (wt \%) }\end{array}$ & $\begin{array}{c}\text { SC } \\
\text { Pith-Raw } \\
(w t \%)\end{array}$ & $\begin{array}{c}\text { SC Pith } \\
\text { Ash-CA } \\
(w t \%)\end{array}$ & $\begin{array}{c}\text { SC } \\
\text { Fiber-Raw } \\
(w t \%)\end{array}$ & $\begin{array}{c}\text { SC Fiber } \\
\text { Ash-CA } \\
\text { (wt } \%)\end{array}$ & $\begin{array}{l}\text { Maize } \\
\text { Leaves- } \\
\text { Raw } \\
(\mathbf{w t} \%)\end{array}$ & $\begin{array}{c}\text { Maize } \\
\text { Leaves } \\
\text { Ash- } \\
\text { CA } \\
(\mathbf{w t} \%)\end{array}$ \\
\hline $\mathrm{SiO}_{2}$ & 63.8 & 87.6 & 95.4 & 99.3 & 39.2 & 94.8 & 33.7 & 94.3 & 51.4 & 93.0 \\
\hline $\mathrm{P}_{2} \mathrm{O}_{5}$ & 1.4 & 0.7 & 0.4 & 0.1 & 1.3 & 1.1 & 4.0 & 2.6 & 5.3 & 3.3 \\
\hline $\mathrm{K}_{2} \mathrm{O}$ & 3.8 & 1.4 & 0.2 & $<\mathrm{LOD}$ & 2.4 & 0.1 & 12.0 & 0.1 & 5.8 & 0.3 \\
\hline $\mathrm{CaO}$ & 14.9 & 7.5 & 2.6 & 0.2 & 19.0 & 0.4 & 14.9 & 0.6 & 21.4 & 1.3 \\
\hline $\mathrm{MgO}$ & 1.5 & 1.2 & 0.4 & $<\mathrm{LOD}$ & 2.2 & 0.3 & 2.9 & 0.9 & 2.0 & 0.4 \\
\hline $\mathrm{SO}_{3}$ & 4.5 & 0.9 & 0.8 & 0.3 & 4.4 & 0.3 & 7.3 & 0.4 & 5.5 & 0.4 \\
\hline $\mathrm{Fe}_{2} \mathrm{O}_{3}$ & 2.3 & 0.2 & 0.1 & $<\mathrm{LOD}$ & 5.7 & 0.9 & 2.5 & 0.2 & 2.4 & 0.3 \\
\hline $\mathrm{Al}_{2} \mathrm{O}_{3}$ & 3.1 & 0.1 & 0.1 & 0.1 & 11.7 & 0.8 & 12.4 & 0.2 & 1.7 & 0.6 \\
\hline $\mathrm{Cl}$ & 1.7 & $<\mathrm{LOD}$ & $<\mathrm{LOD}$ & $<\mathrm{LOD}$ & 5.6 & $<\mathrm{LOD}$ & 6.2 & $<\mathrm{LOD}$ & 0.8 & $<\mathrm{LOD}$ \\
\hline Others $^{a}$ & 3.0 & 0.4 & 0.0 & 0.0 & 8.5 & 1.3 & 4.1 & 0.7 & 3.7 & 0.4 \\
\hline
\end{tabular}

Others: ${ }^{\text {a }}$ Other metal oxides; LOD: limit of detection $=0.1 \mathrm{ppm}$. 
Kumar et al. [24] and Yang et al. [25] reported the degradation of lignin to take place over a wide temperature range of $453-1173 \mathrm{~K}$, concurrent with both the 1 st and 2 nd degradation peaks.

Hence, for the sequential combustion protocol, the first programmed temperature was kept at $583 \mathrm{~K}$ for $30 \mathrm{~min}$ to allow for the removal of residual water from the sample. The second step was performed at $723 \mathrm{~K}$ for $60 \mathrm{~min}$. This focused on thermal degradation of organic components and the transformation of cellulose, hemicellulose, and lignin into carbon $/ \mathrm{CO}_{2}$, which can be noticed by the formation of smoke. However, the smoke ceases after this step. The third step kept the temperature at $783 \mathrm{~K}$ to achieve the complete combustion of carbon in the ash, hence resulting in a white ash [2].

\subsection{The Influence of Leaching on the Chemical and Elemental Composition}

Elemental analysis (CHN) of the untreated biomass and produced silica ash samples was performed to determine their chemical composition, where the focus was on carbon, hydrogen, and nitrogen (Table 2). Three measurements were carried out, an average of each set of analyses was considered and a standard deviation calculated. As expected, the biomass samples have a high carbon content, with the lowest found for untreated sugarcane leaves. Incidentally, sugarcane leaves have the highest ash content and the lowest loss on ignition when compared to the other biomass samples, as shown below. As expected, the thermo-chemical treatment reduces the content of the selected three elements to below $0.5 \mathrm{wt} \%$, as indicated in Table 2 .

Although citric acid is a weaker acid than sulfuric acid, it reduced the carbon content significantly by $>99.7 \%$ for all biomasses, while the nitrogen contents were reduced by $>68.0 \%$, respectively. Citric acid leaching and subsequent combustion produced very white ashes, indicating almost quantitative combustion and removal of organic components. In comparison, pre-treatment of sugarcane leaves with a strong inorganic acid ( $7 \mathrm{wt} \%$ sulfuric acid; -SA) lead to a quantitative removal of carbon, and a reduction of $>97.0 \%$ for nitrogen. In addition, the pre-treatment of sugarcane leaves with hot water (HW) resulted in $99.5 \%$ reduction of carbon and $92.2 \%$ for that of nitrogen.

The chemical analysis of the biomass samples was performed using XRF to study the influence of chemical treatment on the biomass samples. The results obtained are shown in Table 3. The leaching with hot citric acid resulted in white ashes with high silica contents of more than $94 \mathrm{wt} \%$ for all the sugarcane-based biomass samples and $93 \mathrm{wt} \%$ for the maize leaves sample.

The effect of hot water leaching (-HW) was investigated using sugarcane leaves, and it was found that even in the absence of an acid, the silica content in the formed ash increased to $87.6 \mathrm{wt} \%$ while the chlorine was reduced below the detection limit. The extraction of aluminum, iron, and sulfur was as effective as when using citric acid pre-treatment, but hot water leaching was not that effective in the reduction of phosphorus, alkali and alkali earth metals.

When comparing pre-treatments of sugarcane leaves with citric and sulfuric acid, a silica purity of $95.4 \mathrm{wt} \%$ was obtained from citric acid pre-treatment while sulfuric acid pre-treatment resulted in $99.3 \mathrm{wt} \%$ as illustrated in Table 3. This silica content obtained from sulfuric acid pre-treatment of the sugarcane leaves is incredible when compared to those from other agricultural residues. Cereal remnant, wheat straw, and miscanthus were all pre-treated with sulfuric acid and their resulting biogenic silica was reported to be $91.3 \mathrm{wt} \%, 92.8 \mathrm{wt} \%$ and $95.0 \mathrm{wt} \%$, respectively [3]. Alyosef at al. [2] reported a high silica content of $97.7 \mathrm{wt} \%$ from the pre-treatment of rice husk but is still lower than the one reported in this work. Based on the results obtained from this study, it indicates that for applications where a high purity of biogenic silica is essential, only the silica obtained from the pre-treatment of sugarcane leaves with sulfuric acid can be utilized. The biogenic silica obtained through the pre-treatment of sugarcane leaves with citric acid pre-treatment can only be used if the employed thermochemical method is optimized through varying variables like time, temperature, acid concentration, etc. to obtain silica with an increased 
purity. Sulfuric acid leaching resulted in a reduction of potassium, manganese, iron, and chloride below the detection limits. Phosphorus and sulfur were both reduced by $93 \%$, while aluminum and calcium were reduced by 97 and $99 \%$, respectively. For citric acid, phosphorus, alkali earth metals, and sulfur were removed only between $71-83 \%$, while potassium, iron, and aluminum contents were reduced by $95-97 \%$.

It is known that acid treatment leads to the hydrolysis of hemicellulose and cellulose, the degree of which depends on the medium acidity as well as time and temperature. Sulfuric acid treatment is hence a more efficient hydrolysis catalyst, increasing the extractability of inorganics from biomass [26]. However, the extraction selectivity observed for the citric acid-treated sample indicates specific interactions between carboxylic acid groups of citric acid with some the metal ions. These interactions are known to occur by chelation $[9,25-30]$.

The biogenic silica obtained from this study using citric acid as a leaching agent demonstrated a higher purity of silica when compared to the purity of other residues from sugarcane and maize reported in literature. For an example, Worathanakul et al. [31] pre-treated sugarcane bagasse (i.e., a mixture of fiber and pith) with $3 \mathrm{M} \mathrm{HCl}$ to produce biogenic silica with a silica content of $89 \mathrm{wt} \%$ compared to 94.8 and $94.3 \mathrm{wt} \%$ for pith and fiber obtained in this work, respectively. On another study, [32] pre-treated sugarcane bagasse with $1 \mathrm{M} \mathrm{HCl}$ and obtained an even lower silica content of $66 \mathrm{wt} \%$. In yet another recent study a silica content of $85.6 \mathrm{wt} \%$ was obtained from the pre-treatment of sugarcane bagasse with $9 \%$ sulfuric acid [33]. Similarly, for maize leaves pre-treated with $\mathrm{HCl}$, a silica content of $64 \mathrm{wt} \%$ was obtained by Lanning et al. [34], compared to $93 \mathrm{wt} \%$ obtained from this study. Considering the above argument regarding the effect of the acidity of the medium, this finding is somewhat surprising. However, it is noted that the biomass investigated here had been subjected to a sequence of drying, washing, and drying prior to acid treatment, which may affect the efficiency of acid treatment [2]. This demonstrates the incredible ability of hot citric acid pre-treatment in significantly removing/reducing organic compounds and accompanying metal oxides in the biomasses.

\subsection{Phase Identification}

XRD analysis was performed to identify different phases of the produced biogenic silica from the pre-treatment of sugarcane-based biomass (leaves, fiber and pith) and maize leaves as displayed in Figure 2. Judging from the broad peak with an equivalent Bragg angle of $2 \theta$ at $21.8^{\circ}$ of the sugarcane-based samples, it can be deduced that the silica formed was amorphous with almost no traces of crystalline phases [12]. This finding indicates that the combustion protocol is indeed suitable for producing amorphous silica from sugarcane residues. Contrary to this, a presence of additional peaks for biogenic silica produced from maize leaves was observed. These peaks are in addition to the detected broad peak with an intensity of Bragg angle of $2 \theta=21.8^{\circ}$ and the internal standard (CaF2) peaks. This is an indication of the ash not being entirely amorphous. The peaks at $2 \theta=20.9^{\circ}$ and $2 \theta=28.6^{\circ}$ correspond to crystalline silica, quartz to be specific [35]. The presence of quartz in this biogenic silica is suspected to be due to the incomplete removal of the sand/impurities during the washing process.

\subsection{Textural and Structural Properties}

The textural properties of both sugarcane and maize-based biomass samples were obtained from nitrogen sorption measurements (Figure 3). The isotherms have a closed hysteresis loop and consist of a small knee at $\mathrm{p} / \mathrm{p}_{0}=0.05$ that is followed by a continuous increase in the nitrogen uptake. All the biomass ash samples followed a similar pattern categorized as class IV isotherms [16]. 


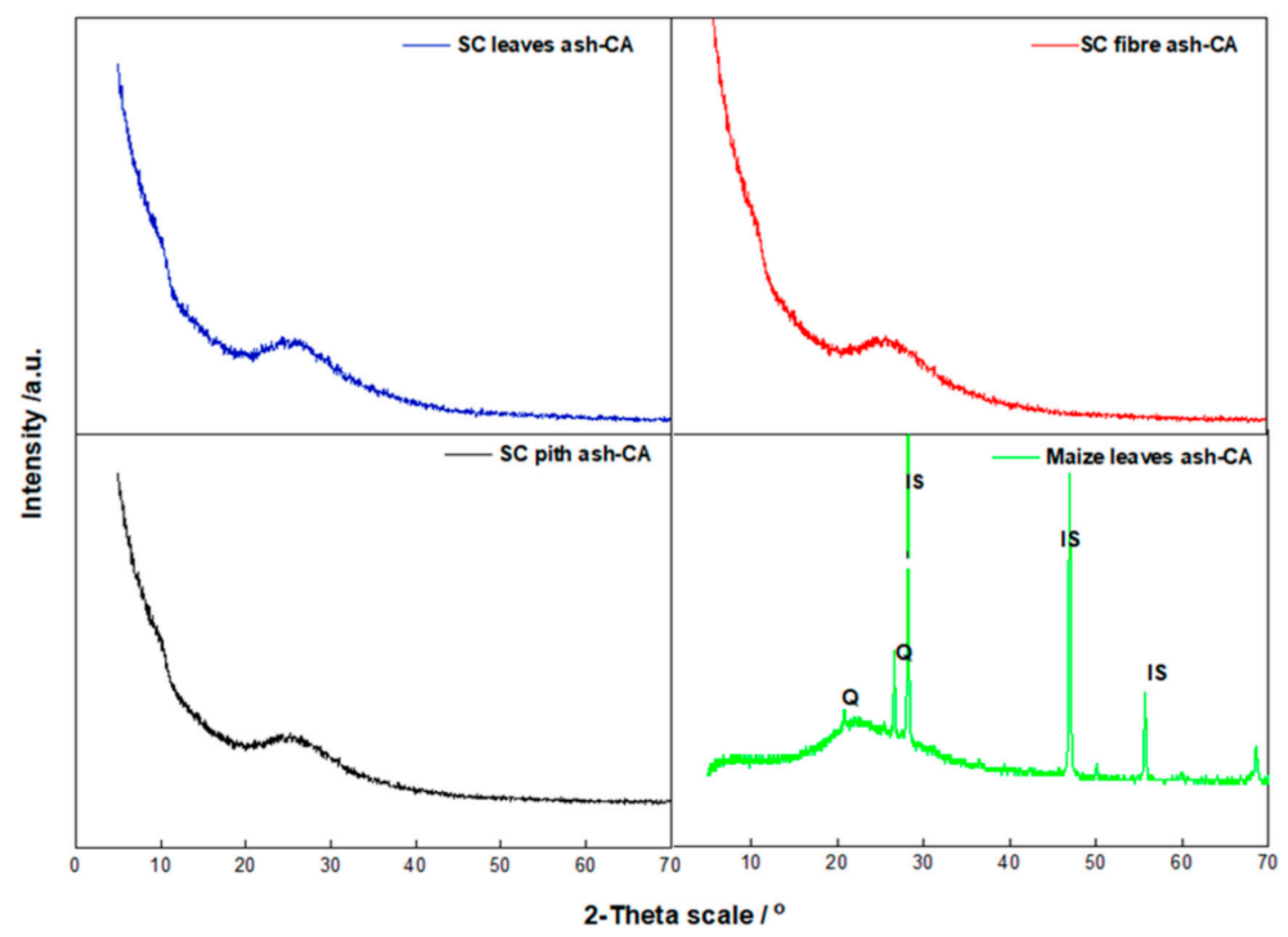

Figure 2. XRD patterns of sugarcane-based biomass (leaves, fiber, and pith) and maize leaves. IS is the internal standard $(\mathrm{CaF} 2)$ and $\mathrm{Q}$ is the quartz.

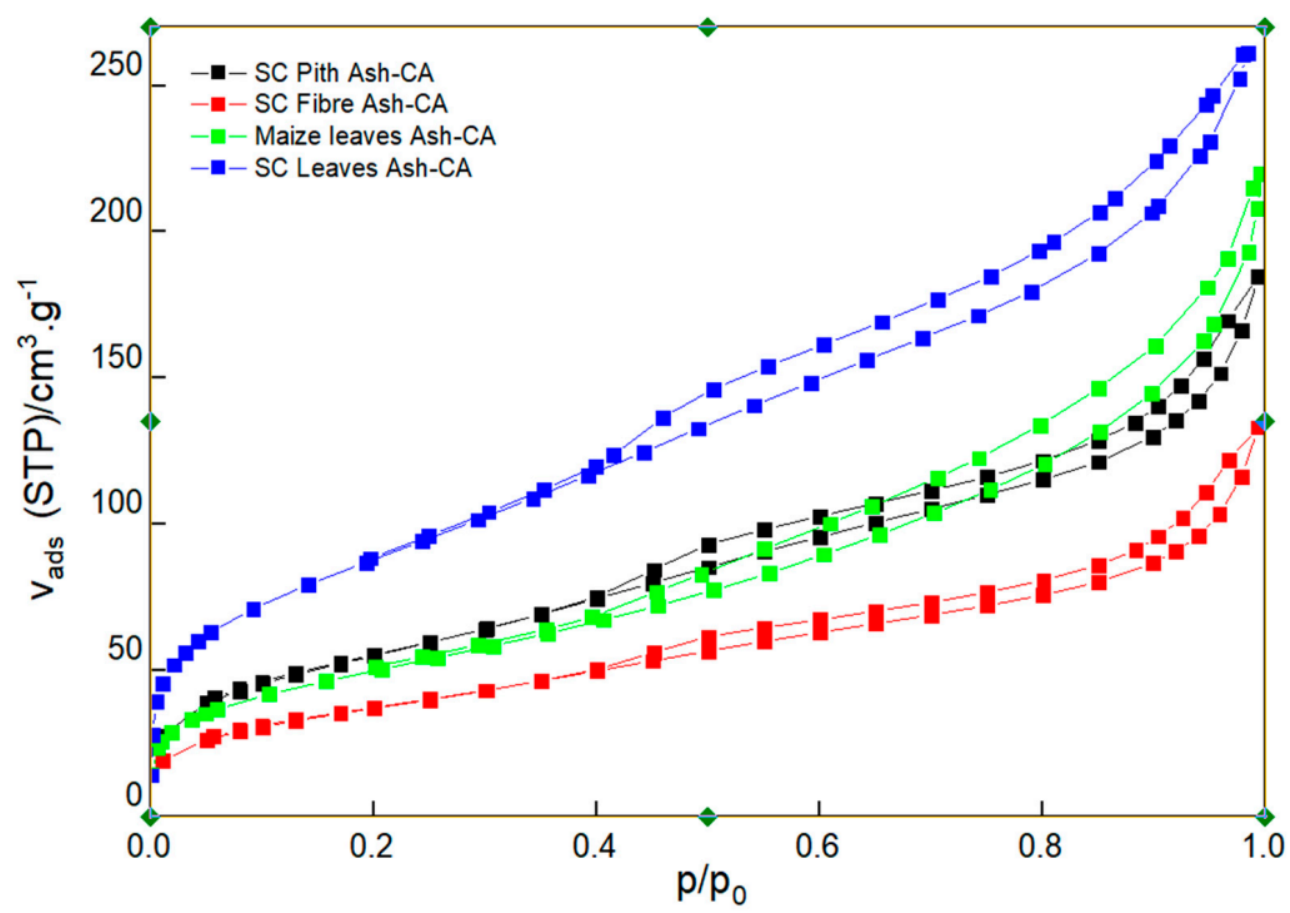

Figure 3. Nitrogen sorption isotherms of biogenic silica derived from sugarcane biomass (leaves, pith and fiber) and maize leaves.

The particle pores can either be micropores $(\leq 2 \mathrm{~nm})$, mesopores $(2-50 \mathrm{~nm})$ or macropores $(\geq 50 \mathrm{~nm})$. Each of these is characterized with a specific adsorption isotherm. The opening of micropores consists of a diameter of a few molecules and that causes the poten- 
tial fields of the connection pore walls to overlap with one another [36]. The interaction between the adsorbent and the molecule is therefore automatically intensified, which results in a steep increase in adsorption quantity even at low relative pressures. The adsorption, however, levels off eventually due to the achieved saturation pressure [37], resulting in a long plateau in the isotherm over a wide range of relative pressures [35]. There is a presence of a hysteresis loop with a lower closure point at about $\mathrm{p} / \mathrm{p}_{0}=0.42-0.45$, which can be classified as H3 [37] as is the case for all four examined samples of biomass ash samples. This indicates that there is a presence of additional macropores and also stipulates that accessibility of the larger mesopores can only be through the smaller mesopores [4]. In the case of the sugarcane leaves ash sample (citric acid-treated), additional microporosity cannot be excluded. In addition, none of the isotherms reach a plateau at high $\mathrm{p} / \mathrm{p}_{0}=1$ values. This is a characteristic for incomplete pore filling by an adsorbate and suggests that larger meso- and macropores are also present in the materials $[4,36]$.

The textural properties, including BET surface area (ABET), average pore size (Dp), and pore volume (Vmeso) of all porous silica products are given in Table 4 . The citric acid pre-treated sugarcane leaves ash sample is characterized by the largest BET surface area of $323 \mathrm{~m}^{2} \cdot \mathrm{g}^{-1}$. This is quite a competitive specific surface area when comparing it with that of other agricultural residues from the literature: rice husk ash and cereal remnants, after pre-treatment with citric acid, showed specific surface areas of $313 \mathrm{~m}^{2} \cdot \mathrm{g}^{-1}$ [2] and $245 \mathrm{~m}^{2} \cdot \mathrm{g}^{-1}$ [3], respectively. Citric acid leached sugarcane fiber, pith and maize leaves had BET surface areas of 136, 203 and $182 \mathrm{~m}^{2} \cdot \mathrm{g}^{-1}$. Even though sugarcane fiber and the pith are from the same material (bagasse), their textural properties differ. The average pore diameter of the produced ash is $5 \mathrm{~nm}$ for sugarcane leaves, both sugarcane pith and fiber have $6 \mathrm{~nm}$ while the maize leaves have an average pore diameter of $7 \mathrm{~nm}$. Sugarcane fiber has the lowest pore volume of $0.21 \mathrm{~cm}^{3} \cdot \mathrm{g}^{-1}$, while sugarcane leaves show the highest value of $0.41 \mathrm{~cm}^{3} \cdot \mathrm{g}^{-1}$.

Table 4. Textural properties of sugarcane and maize-based biomass ash samples (determined by nitrogen sorption).

\begin{tabular}{cccc}
\hline Sample & $\mathbf{A}_{\mathbf{B E T}}\left(\mathbf{m}^{\mathbf{2}} \mathbf{g}^{-\mathbf{1}}\right)$ & $\left.\mathbf{D}_{\mathbf{p}} \mathbf{( n m}\right)$ & $\mathbf{V}_{\text {meso }}\left(\mathbf{c m}^{\mathbf{3}} \mathbf{g}^{-\mathbf{1}} \mathbf{)}\right.$ \\
\hline SC leaves Ash-CA & 323 & 5.0 & 0.41 \\
SC leaves Ash-SA & 326 & 4.7 & 0.47 \\
SC leaves Ash-HW & 133 & 8.0 & 0.25 \\
SC Pith Ash-CA & 203 & 6.0 & 0.29 \\
SC Fiber Ash-CA & 136 & 6.0 & 0.21 \\
Maize leaves Ash-CA & 182 & 7.0 & 0.34 \\
\hline
\end{tabular}

The effect of hot water and sulfuric acid leaching on the textural properties was also investigated using sugarcane leaves. Although the BET surface area of hot water leached sugarcane leaves is relatively low $\left(133 \mathrm{~m}^{2} \mathrm{~g}^{-1}\right)$, with average pore diameter of $8.0 \mathrm{~nm}$ and a pore volume of $0.25 \mathrm{~cm}^{3} \mathrm{~g}^{-1}$, it is noteworthy that it is similar to that of citric acid-treated sugarcane fiber. Compared to citric acid pre-treatment, sulfuric acid leaching resulted in a slight increase of BET surface area $(0.9 \%)$ but decreased the pore diameter by $6 \%$ while the pore volume increased by $15 \%$. It can be stated that the biogenic silica ashes produced from sugarcane leaves with either citric or sulfuric acid fall within the specifications of commercial products such as silica gels $\left(\mathrm{ABET}=250-1000 \mathrm{~m}^{2} \mathrm{~g}^{-1}\right.$, DP $=2-20 \mathrm{~nm}$, narrow pore width distribution) [38].

The pore size distribution of the pre-treated biomass samples was also determined using the adsorption branch of the nitrogen sorption isotherms (Figure 4), indicating a broad pore size distribution of disordered meso and macropores. 


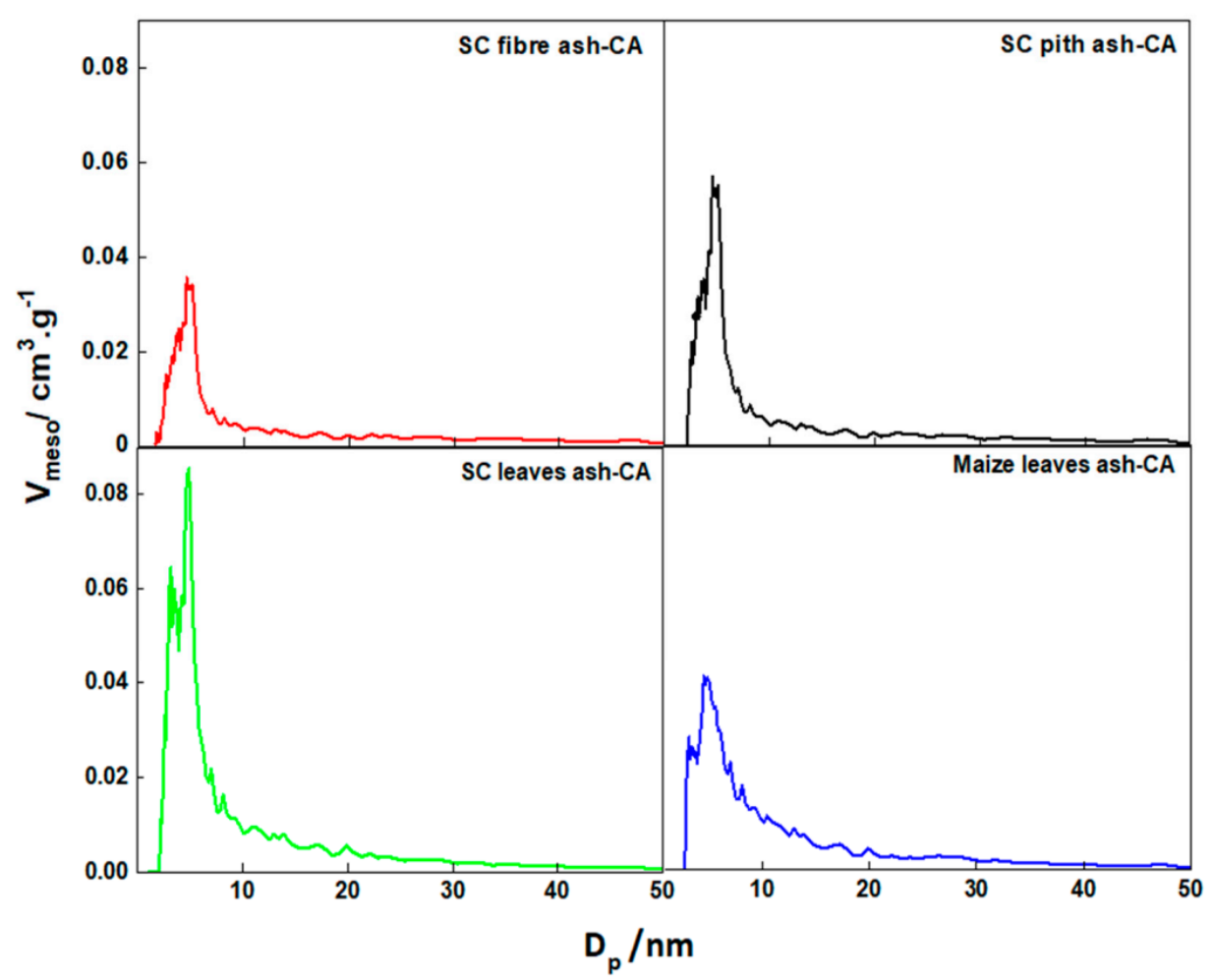

Figure 4. Pore size distribution of biogenic silica derived from sugarcane biomass (fiber, pith and leaves) and maize leaves (determined by an adsorption branch of nitrogen sorption isotherms).
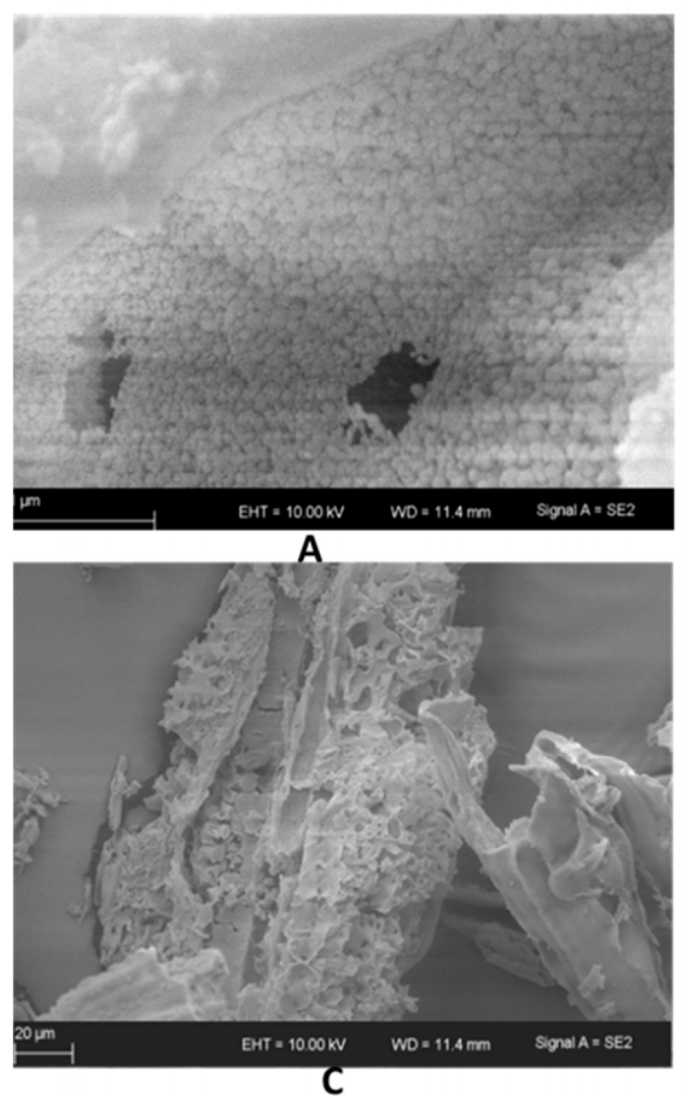

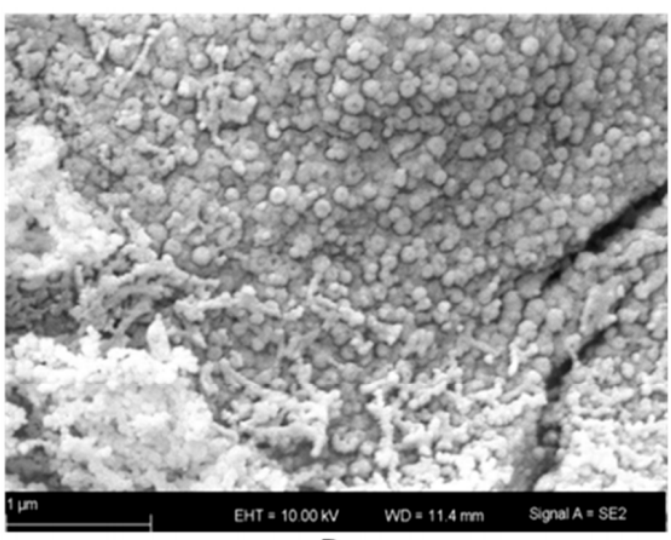

B

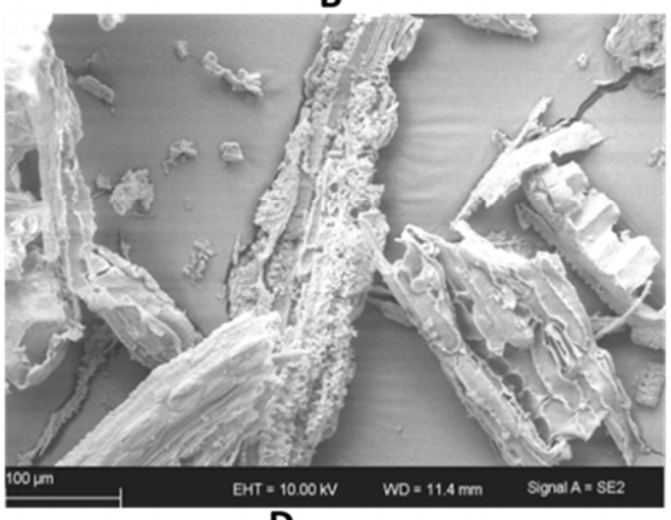

D

Figure 5. SEM pictures of biogenic silica derived from sugarcane leaves after pre-treatment with citric acid and subsequent burning from different parts of inner epidermis with high (A,B), intermediate (C) and low magnification (D). 
Figure 5A-D show the SEM images of the produced ash from sugarcane leaves leached with citric acid, demonstrating that the produced biogenic silica ash possesses numerous types of pore shapes and sizes. Figure $5 \mathrm{~A}$ visualizes the evident porosity of the ash at higher magnification while Figure $5 \mathrm{~B}$ indicates agglomeration of small particles. Intraparticle meso- and macropores can be observed from Figure 5A. Figure 5C (intermediate magnification) and Figure 5D (low magnification) show a broken inner epidermis from different parts with several shapes such as double rods and backbone structure. However, these fragments seem to have retained their original structure. In addition, a smooth surface is observed.

Figure 6A-D present the SEM images of biogenic silica ash resulting from the pretreatment of maize leaves with citric acid, indicating the presence of different pore shapes and sizes. Figure $6 \mathrm{~A}$ demonstrates intraparticle macropores in inner epidermis at a high magnification. Figure 6B shows agglomeration of small particles, while Figure 6C,D show the broken structure of the inner epidermis that has an intact silicified structure, and this is shown from different parts in different magnifications.

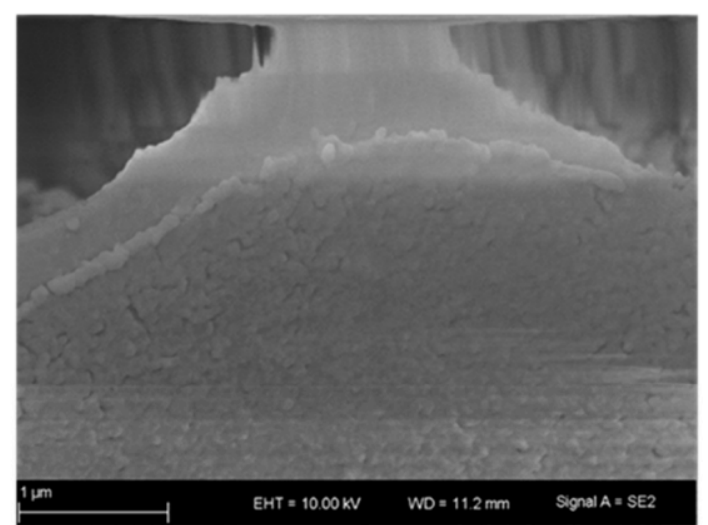

A

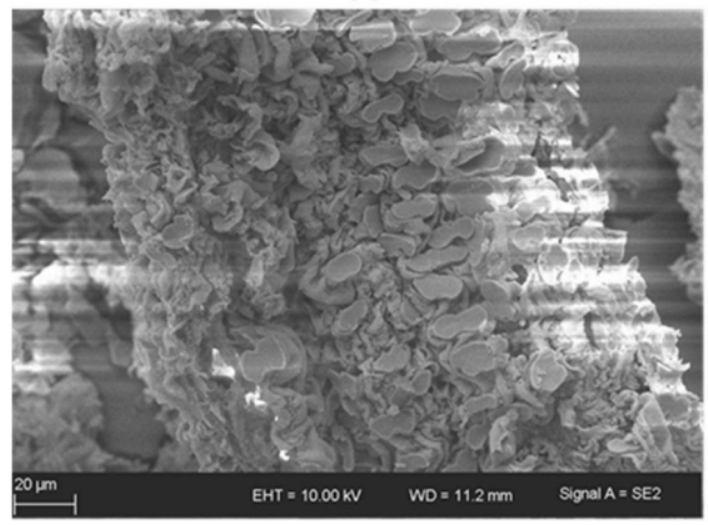

C

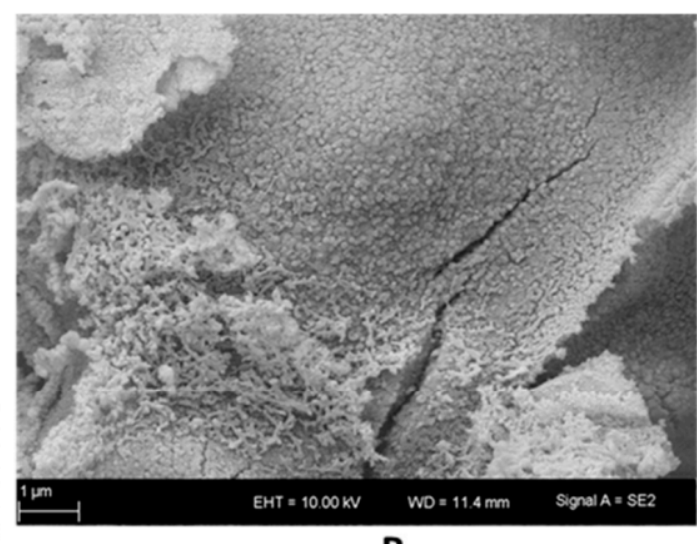

B

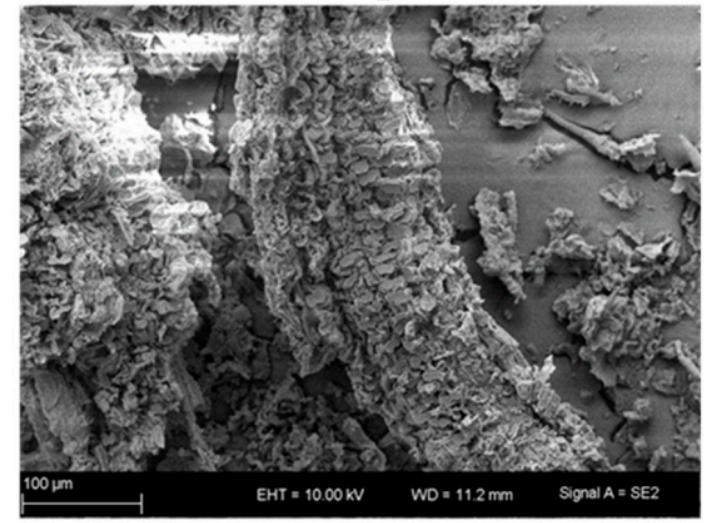

D

Figure 6. SEM pictures of biogenic silica derived from maize leaves after pre-treatment with citric acid and subsequent burning from different parts of inner epidermis with high $(\mathbf{A}, \mathbf{B})$, intermediate $(\mathbf{C})$ and low magnification (D).

\section{Conclusions}

This study demonstrates the production of biogenic silica with high purity $(99.3 \mathrm{wt} \%$ silica content) and exceptional textural properties. Different South African agricultural residues (sugarcane leaves, pith and fiber, as well as maize leaves) were utilized for the first time in the production of amorphous biogenic silica through a thermo-chemical procedure that employed hot citric acid leaching and subsequent combustion. Furthermore, the possibility of using sugarcane-based materials as an additional feedstock in the production of biogenic silica was demonstrated. 
When compared to sulfuric acid, citric acid pre-treatment of sugarcane leaves resulted in fully amorphous silica with excellent quality, with $99.7 \%$ removal of carbon and $95.4 \mathrm{wt} \%$ silica content, which is higher than the purity obtained from other agricultural residues in the literature such as wheat straw, miscanthus and cereal remnant [3]. While the removal of inorganic impurities was somewhat less efficient with citric acid than with sulfuric acid pre-treatment (silica content of $99.3 \mathrm{wt} \%$ vs. $95.4 \mathrm{wt} \%$ ), similar textural properties (323 $\mathrm{m}^{2} \mathrm{~g}^{-1}$ surface area, $5.0 \mathrm{~nm}$ average pore diameter and $0.41 \mathrm{~cm}^{3} \mathrm{~g}^{-1}$ pore volume) were still obtained from the produced amorphous biogenic silica. The advantage of citric acid lies in it being an organic and bio-based acid, which affects both costs of effluent treatment and material of construction when compared to strong mineral acids such as sulfuric or hydrochloric acid.

When comparing the citric acid pre-treatment of all the utilized biomasses, the sugarcane-based starting materials resulted in biogenic silica with higher purity (94.3-95.4 $\mathrm{wt} \%$ ) compared to that of maize leaves (93.0 $\mathrm{wt} \%)$. Sugarcane leaves provided a material that consisted of best textural properties than sugarcane fiber and pith, as well as maize leaves.

Our study focused on biogenic silica production; hence, future research will investigate if an additional extraction step with citric acid could lead to further improvement regarding the removal of inorganic impurities.

Considering the high sugar production in South Africa with an export markets in Africa, the Middle East, Korea, Japan, and the North America, the continuous generation of sugarcane trash is predicted to increase. Therefore, sugarcane-based starting materials can be used to expand the feedstock for the production of biogenic silica. In addition, the production of biogenic silica from sugar cane trash will be a plus in solving disposal problems, and thus contribute to the mitigation of climate change and other environmental impacts that could result from the burning of its trash.

Finally, with growing potentials and opportunities of sugarcane agricultural residues in sugarcane-growing countries like South Africa, our future research will assess the effect of upscaling on the morphology of the products in terms of the potential of generating energy during combustion while producing biogenic silica, especially from sugarcane leaves.

Author Contributions: Conceptualization, S.W. and A.S.; Data curation, N.N.M., D.S. and S.W.; Investigation, N.N.M., Methodology, D.S. and D.E.; Supervision, D.E., S.A.I., J.P. and A.S.; Validation, D.E.; Visualization, D.E., S.A.I. and A.S.; Writing-original draft preparation, N.N.M.; Writing-review and editing, D.S., D.E., S.A.I., J.P., and A.S., funding acquisition, National Research Foundation of South Africa. All authors have read and agreed to the published version of the manuscript.

Funding: This research was funded in part by the National Research Foundation of South Africa, grant number 115465.

Acknowledgments: We appreciate EUROSA scholarship for enabling the collaboration that made this manuscript possible. We thank the Sugar Milling Research Institute (SMRI) for the provision of sugarcane pith and fiber, W. Bernhardt (UKZN) for sourcing sugarcane leaves and R. Denecke (University of Leipzig) for laboratory support.

Conflicts of Interest: The authors declare no conflict of interest.

\section{References}

1. Umeda, J.; Kondoh, K.; Michiura, Y. Process Parameters Optimization in Preparing High-Purity Amorphous Silica Originated from Rice Husks. Mater. Trans. 2007, 48, 3095-3100. [CrossRef]

2. Alyosef, H.A.; Eilert, A.; Welscher, J.; Ibrahim, S.S.; Denecke, R.; Schwieger, W.; Enke, D. Characterization of Biogenic Silica Generated by Thermo Chemical Treatment of Rice Husk. Part. Sci. Technol. 2013, 31, 524-532. [CrossRef]

3. Alyosef, H.A.; Schneider, D.; Wassersleben, S.; Roggendorf, H.; Weiß, M.; Eilert, A.; Denecke, R.; Hartmann, I.; Enke, D. Meso/Macroporous Silica from Miscanthus, Cereal Remnant Pellets, and Wheat Straw. ACS Sustain. Chem. Eng. 2015, 3, 2012-2021. [CrossRef]

4. Schneider, D.; Wassersleben, S.; Weiß, M.; Denecke, R.; Stark, A.; Enke, D. A Generalized Procedure for the Production of High-Grade, Porous Biogenic Silica. Waste Biomass Valorization 2020, 11, 1-15. [CrossRef] 
5. Okoronkwo, E.A.; Imoisili, P.E.; Olubayode, S.A.; Olusunle, S.O.O. Development of Silica Nanoparticle from Corn Cob Ash. Adv. Nanopart. 2016, 5, 135-139. [CrossRef]

6. Alyosef, H.A.; Ibrahim, S.; Welscher, J.; Inayat, A.; Eilert, A.; Denecke, R.; Schwieger, W.; Münster, T.; Kloess, G.; Einicke, W.D.; et al. Effect of acid treatment on the chemical composition and the structure of Egyptian diatomite. Int. J. Miner. Process. 2014, 132, 17-25. [CrossRef]

7. Kootstra, A.M.J.; Beeftink, H.H.; Scott, E.L.; Sanders, J.P. Comparison of dilute mineral and organic acid pretreatment for enzymatic hydrolysis of wheat straw. Biochem. Eng. J. 2009, 46, 126-131. [CrossRef]

8. Yalçin, N.; Sevinç, V. Studies on silica obtained from rice husk. Ceram. Int. 2001, 27, 219-224. [CrossRef]

9. Mupa, M.; Hungwe, C.B.; Witzleben, S.; Mahamadi, C.; Muchanyereyi, N. Extraction of silica gel from Sorghum bicolour (L.) moench bagasse ash. Afr. J. Pure Appl. Chem. 2015, 9, 12-17. [CrossRef]

10. Umeda, J.; Kondoh, K. High-purity amorphous silica originated in rice husks via carboxylic acid leaching process. J. Mater. Sci 2008, 43, 7084-7090. [CrossRef]

11. Le Blond, J.S.; Horwell, J.C.; Williamson, B.J.; Oppenheimer, C. Generation of crystalline silica from sugarcane burning. J Env. Monit. 2010, 12, 1459-1470. [CrossRef]

12. Musić, S.; Filipović-Vinceković, N.; Sekovanić, L. Precipitation of amorphous $\mathrm{SiO}_{2}$ particles and their properties. Braz. J. Chem. Eng. 2011, 28, 89-94. [CrossRef]

13. Sisuka, W. Annual South African Sugar Production Forecast to Grow Despite Revenue Pressures. Available online: https:/ /apps.fas.usda.gov/newgainapi/api/report/downloadreportbyfilename?filename=Sugar\%20Annual_Pretoria_ South\%20Africa\%20-\%20Republic\%20of_4-15-2019.pdf (accessed on 11 January 2021).

14. Chandel, A.; Da Silva, S.; Carvalho, W.; Singh, O. Sugarcane bagasse and leaves: Foreseeable biomass of biofuel and bio-products. J. Chem. Technol. Biotech. 2011, 87, 11-20. [CrossRef]

15. Smithers, J. Review of sugarcane trash recovery systems for energy cogeneration in South Africa. Renew. Sustain. Energy Rev. 2014, 32, 915-925. [CrossRef]

16. Du Plessis, J. Maize Production; Department of Agriculture South Africa: Pretoria, South Africa, 2003.

17. Wilkonson, D. Industrial guidelines for burning sugarcane. In SASRI Information Sheets; Sugar Research Institute: Durban, South Africa, 2013; pp. 1-2.

18. Street, R.A. Technology and Applications of Amorphous Silicon; Springer: Berlin, Germany, 2000.

19. Joshi, H.H.; Gertz, R.E.; Carvalho, M.D.G.; Beall, B.W. Use of silica desiccant packets for specimen storage and transport to evaluate pneumococcal nasopharyngeal carriage among nepalese children. J. Clin. Microbiol. 2008, 46, 3175-3176. [CrossRef]

20. Joiner, A. A silica toothpaste containing blue covarine: A new technological breakthrough in whitening. Int. Dent. J. 2009, 59, 284-288. [CrossRef]

21. Yu, D.P.; Hang, Q.L.; Ding, Y.; Zhang, H.Z.; Bai, Z.G.; Wang, J.J.; Zou, Y.H.; Qian, W.; Xiong, G.C.; Feng, S.Q. Amorphous silica nanowires: Intensive blue light emitters. Appl. Phys. Let. 1998, 73, 3076-3078. [CrossRef]

22. Carmona, V.; Oliveira, R.; Silva, W.; Mattoso, L.; Marconcini, J. Nanosilica from rice husk: Extraction and characterization. Ind. Crop. Prod. 2013, 43, 291-296. [CrossRef]

23. Barrett, E.; Joyner, L.; Halenda, P. The determination of pore volume and area distributions in Porous Substances. I. computations from nitrogen isotherms. J. Am. Chem. Soc. 1951, 73, 373-380. [CrossRef]

24. Kumar, A.; Wang, L.; Dzenis, Y.A.; Jones, D.D.; Hanna, M.A. Thermogravimetric characterization of corn stover as gasification and pyrolysis feedstock. Biomass Energy 2008, 32, 460-467. [CrossRef]

25. Yang, H.; Yan, R.; Chen, H.; Lee, D.; Zheng, C. Characteristics of hemicellulose, cellulose and lignin pyrolysis. Fuel 2007, 86, 1781-1788. [CrossRef]

26. Liou, T. Preparation and characterization of nano-structured silica from rice husk. Mater. Sci. Eng. 2004, 364, 313-323. [CrossRef]

27. Fang, F. Pretreatment Techniques for Biofuels and Biorefineries, 1st ed.; Springer: Berlin/Heidelberg, Germany, $2015 ;$ pp. 158-159.

28. Umeda, J.; Imai, H.; Kondoh, K. Polysaccharide hydrolysis and metallic impurities removal behavior of rice husks in citric acid leaching treatment. Trans. JWRI 2009, 38, 13-18.

29. Faizul, C.; Chik, A.; Bari, M.; Noorina, H. Extraction of silica from palm ash using organic acid leaching treatment. Key Eng. Mat. 2013, 7, 3690-3695. [CrossRef]

30. Boochapun, S.; Lamamorphanth, W.; Kamwilaisak, K. The acid hydrolysis of sugarcane leaves as a biofeedstook for bioethanol production. Adv. Mater. Res. 2014, 931-932, 194-199. [CrossRef]

31. Worathanakul, P.; Payubnop, W.; Muangpet, A. Characterization for post-treatment effect of bagasse ash for silica extraction. World Acad. Sci. Eng. Technol. 2009, 3, 339-341. [CrossRef]

32. Chindaprasirt, P.; Rattanasak, U. Eco-production of silica from sugarcane bagasse ash for use as a photochromic pigment filler. Sci. Rep. 2020, 10, 1-8. [CrossRef]

33. Sholeh, M.; Rochmadi, R.; Sulistyo, H.; Budhijanto, B. Synthesis of precipitated silica from bagasse ash as reinforcing filler in rubber. In IOP Conference Series: Materials Science and Engineering; IOP Publishing: Kuala Lumpur, Malaysia, 2020; Volume 778, p. 012012. [CrossRef]

34. Lanning, F.; Ponnaiya, B.; Crumpton, C. The chemical nature of silica in plants. Plant Physiol. 1958, 33, 339-343. [CrossRef]

35. Chisholm, J. Comparison of Quartz Standards for X-ray Diffraction Analysis: HSE A9950 (Sikron F600) and NIST SRM 1878. Ann. Occup. Hyg. 2005, 49, 351-358. [CrossRef] 
36. Kumar, R.; Bhattacharjee, B. Porosity, pore size distribution and in situ strength of concrete. Cem. Concr. Res. 2003, 33, 155-164. [CrossRef]

37. Thommes, M.; Kaneko, K.; Neimark, A.V.; Olivier, J.P.; Rodriguez-Reinoso, F.; Rouquerol, J.; Sing, K.S. Physisorption of gases, with special reference to the evaluation of surface area and pore size distribution (IUPAC Technical Report). Pure Appl. Chem. 2015, 87, 1051-1069. [CrossRef]

38. Ferch, H. Pulverförmige amorphe synthetische Kieselsäure-Produkte Herstellung und Charakterisierung. Chem. Ing. Tech. 1976, 48, 922-933. [CrossRef] 